\title{
Effect of Aqueous Extract from Morinda officinalis F. C. How on Microwave-Induced Hypothalamic-Pituitary-Testis Axis Impairment in Male Sprague-Dawley Rats
}

\author{
Bin Song, ${ }^{1,2,3}$ Fengjuan Wang, ${ }^{4}$ and Wei Wang ${ }^{1,2,3}$ \\ ${ }^{1}$ Department of Human Anatomy and Histoembryology, School of Basic Medical Sciences, Fujian Medical University, \\ Fuzhou 350108, China \\ ${ }^{2}$ Key Laboratory of Brain Aging and Neurodegenerative Diseases of Fujian Provincial Universities and Colleges, Fuzhou 350108, China \\ ${ }^{3}$ Research Center for Neuroscience, Fujian Medical University, Fuzhou 350108, China \\ ${ }^{4}$ Department of Breast Surgery, First Ailiated Hospital of Xiamen University, Xiamen 361003, China
}

Correspondence should be addressed to Wei Wang; wangwei@fjmu.edu.cn

Received 29 July 2015; Accepted 18 August 2015

Academic Editor: Settimio Grimaldi

Copyright (C) 2015 Bin Song et al. This is an open access article distributed under the Creative Commons Attribution License, which permits unrestricted use, distribution, and reproduction in any medium, provided the original work is properly cited.

The present study aimed to assess the protective effects of aqueous extract from Morinda officinalis F. C. How on microwaveinduced reproductive impairment in male rats. Microwave exposure injury was induced by exposure of $900 \mathrm{MHz}$ microwaves at $218 \mu \mathrm{m} / \mathrm{cm}^{2}$ radiation densities, 24 hours/day for 10 days. Male Sprague-Dawley rats were randomized to: normal control, microwave exposure model, or water layer or ethyl acetate layer of aqueous extract $40 \mathrm{~g} / \mathrm{kg}$ treatment groups. After 2 weeks of treatment, sexual performance, serum levels of gonadotrophin-releasing hormone ( $\mathrm{GnRH})$, luteinizing hormone (LH), follicle-stimulating hormone (FSH) or testosterone, morphological analysis of testis and epididymis, and $\mathrm{GnRH}$ protein expression in the hypothalamus were measured. Pretreatment with water layer of aqueous extract $40 \mathrm{~g} / \mathrm{kg}$ significantly improved sexual performance, increased serum testosterone level, and decreased LH and GnRH level compared with microwave exposed model rats (all $P<0.05$ ). Water layer of aqueous extract treatment significantly increased seminiferous cell or sperm number in testis and epididymis. Protein expression of GnRH in the hypothalamus significantly decreased in the water layer of aqueous extract treated group $(P<0.05)$. Ethyl acetate layer of aqueous extract did not show obvious effects on the measured parameters. These findings suggest that water layer of aqueous extract $40 \mathrm{~g} / \mathrm{kg}$ ameliorates microwave-reduced reproductive impairment.

\section{Introduction}

Male infertility is a global population health concern. Approximately $15 \%$ of couples have difficulty conceiving, and male factor contributes to $40-60 \%$ of those cases $[1,2]$. The most common cause of male infertility is loss of sufficient normal, active sperm [3]. Microwaves from mobile phones can be added to the environmental factors that contribute to male infertility $[4,5]$. Exposure to cell phone microwaves may decrease sperm parameters [6]. Therefore, prevention and treatment of microwave-induced male reproductive impairments urgently need to be addressed.

The underlying mechanisms of microwave-induced reproductive impairment in males are largely unknown.
The hypothalamic-pituitary-testicular axis represents a complex neuroendocrine feedback loop regulating reproductive function. Gonadotropin-releasing hormone $(\mathrm{GnRH})$, a hormone produced by specific neurons in the hypothalamus, forms the final common pathway regulating reproductive function [7]. GnRH induces synthesis and secretion of the luteinizing hormone (LH) and follicle-stimulating hormone (FSH). FSH is responsible for the activation of the seminiferous tubules and production of sperm. Testicular function is controlled by the central nervous system via FSH and LH. Testosterone is positively linked with sexual intimacy in men [8] and plays a significant role in spermatogenesis in adult males. 
The male reproductive system is highly susceptible to microwave radiations [9]. Microwaves from mobile phones located nearby the testicular organs can penetrate testicular tissues. In addition, the central nervous system is susceptible to microwave exposure $[10,11]$. Microwaves may have both thermal and nonthermal effects on the reproductive tissues [12], which may lead to decreased sperm count, enzymatic and hormonal changes, DNA damage, and apoptosis formation [13].

There have been many attempts to reduce adverse effects of microwave radiations through use of herbal drugs. The root of Morinda officinalis F. C. How is widely used for the treatment of sexual dysfunctions in China and has a potential role in the maintenance of male reproduction. Treatment with crude drug of Morinda officinalis F. C. How increased sperm activity and sperm density [14]. Both aqueous and alcohol extracts of Morinda officinalis F. C. How could promote spermatogenesis and repair reproductive injury induced by microwave radiation $[15,16]$. Many bioactive constituents are isolated from Morinda officinalis F. C. How such as anthraquinone, carbohydrate constituents, betasitosterol, and ethylcholesterol [17]. The invigorating KidneyYang effect of Morinda officinalis F. C. How derives mainly from the fraction of water and ethyl acetate solvent extraction [18]. However, the effective fraction of Morinda officinalis F. C. How against microwave-induced reproductive impairment is not clear.

We aimed to investigate the protective effects of ethyl acetate layer and water layer fraction of aqueous extract derived from Morinda officinalis F. C. How on microwaveinduced reproductive impairment in male rats.

\section{Material and Methods}

2.1. Materials. Twenty-four male healthy Sprague-Dawley rats ( 4 months old, weighing $247.7 \pm 13.6 \mathrm{~g}$ ) were obtained from the Animal Experiment Center of Fujian Medical University (certificate number: SCXK [Min] 2012-0001). The rats were housed in a temperature controlled room $\left(18^{\circ} \mathrm{C}-\right.$ $24^{\circ} \mathrm{C}$ ) and $45-65 \%$ humidity on a $12 \mathrm{~h}$ light and $12 \mathrm{~h}$ darkness cycle. All rats were fed a standard diet and had free access to water. The dried roots of Morinda officinalis F. C. How were purchased from the rural commercial association of Yongding, China, and the plant was authenticated by herbal expert L. Zheng of rural commercial association of Yongding. The GnRH, LH, FSH, and testosterone enzyme linked immunosorbent assay (ELISA) kits were all purchased from R\&D Co. Ltd. Rabbit polyclonal anti-GnRH (ab5617) was purchased from Abcam Biological Products Co. Ltd. Donkey anti-rabbit green fluorescent antibody (A21206) was from Invitrogen Co. Ltd. of USA and 4,6-diamidino-2phenylindole (DAPI) was obtained from Sigma-Aldrich Co. Ltd.

\subsection{Preparation of Aqueous Extract Derived from Morinda} officinalis F. C. How. Dried Morinda officinalis F. C. How roots were ground to fine powder and boiled with 10- and 6fold volumes of water at $100^{\circ} \mathrm{C}$ for $2 \mathrm{~h}$. The combined crude extracts suspension was then filtered with filter paper and

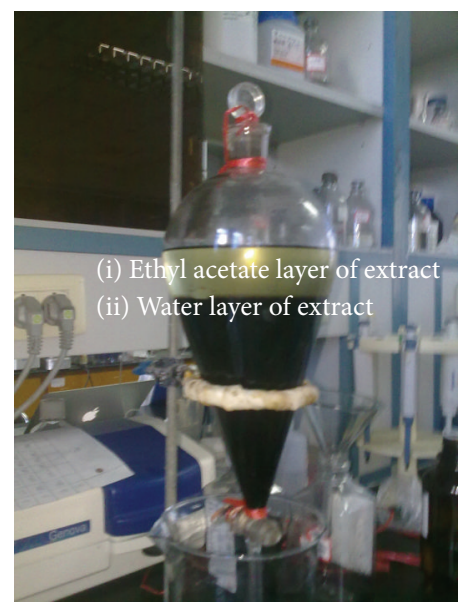

Figure 1: Water layer and ethyl acetate layer fraction of aqueous extract derived from Morinda officinalis F. C. How. The upper shallow yellow solution is the ethyl acetate layer fraction; lower dark brown solution is the water layer fraction.

evaporated on a rotatory evaporator under reduced pressure. The condensed extract, $500 \mathrm{~mL}$, was mixed with $500 \mathrm{~mL}$ ethyl acetate in a 1,000 $\mathrm{mL}$ separating funnel. After $30 \mathrm{~min}$ of being stationary, the solution divided into 2 layers: ethyl acetate layer fraction (upper shallow yellow solution) and water layer fraction (lower dark brown solution) of the aqueous extract (Figure 1). Finally, the water layer or ethyl acetate layer fraction was collected separately for the subsequent experiments. In this paper, the dose of ethyl acetate layer or water layer fraction of aqueous extract $40 \mathrm{~g} / \mathrm{kg}$ was expressed in terms of dried weight of the plant to body weight.

2.3. Experimental Protocol. All experimental protocols were approved by the laboratory animal center of the Academy of Fujian Medical University and carried out by the Guidelines of Care and Use of Laboratory Animals. Twenty-four rats were randomized equally to four groups: normal control group, microwave exposure model group, microwave exposure plus ethyl acetate layer fraction $40 \mathrm{~g} / \mathrm{kg}$ treatment group, and microwave exposure plus water layer fraction $40 \mathrm{~g} / \mathrm{kg}$ treatment group. Rats in the treatment group were orally administered $40 \mathrm{~g} / \mathrm{kg}$ ethyl acetate layer fraction or water layer fraction at the end of microwave exposure consecutively for 10 days, whereas rats in the normal control and microwave exposure model groups orally received the same volume of saline.

Rats receiving microwave exposure were placed in a Plexiglas cage (six rats at a cage). The cage was covered with a homemade tin box at $50 \mathrm{~cm} \times 50 \mathrm{~cm} \times 50 \mathrm{~cm}$. The opening of the cage was faced by the horn antenna in a $10 \mathrm{~cm}$ distance. Rats were exposed to $900 \mathrm{MHz}$ of continuous microwave through a microwave signal generator (Quanzhou Rongshengda telecommunications Co., China), $24 \mathrm{~h} /$ day for 10 days. The radiation density of the cage was $218 \mu \mathrm{m} / \mathrm{cm}^{2}$ under a ML-91 microwave leakage tester (Suqian Jingchen radio equipment Co. Ltd., China). 
2.4. Sample Collection and Preparation. At the end of the experimental period, rats were weighed and sacrificed under anesthesia with an intraperitoneal injection of $4-6 \mathrm{mg} / \mathrm{kg}$ $10 \%$ chloral hydrate. Blood samples $(3 \mathrm{~mL})$ were collected from the right atrium and then centrifuged at 2,500 r/min for $15 \mathrm{~min}$. The serum was stored at $-20^{\circ} \mathrm{C}$ for the enzyme assays. Testis and epididymis were excised and cleared of adhering connective tissues. Testis and epididymis were fixed in $4 \%$ polyformaldehyde and picric acid for histopathological analysis. Brain including hypothalamic tissues was dissected out and stored in $30 \%$ sucrose solution at $4^{\circ} \mathrm{C}$ for subsequent frozen section and immunofluorescence staining.

2.5. Sexual Performance. At the end of treatment, the experimental rats were placed in a $45 \times 25 \times 20 \mathrm{~cm}$ cage and were allowed to adapt to the cage environment for $5 \mathrm{~min}$. The same number of healthy female rats was then added to the cage. Two observers separately recorded the capture incubation period (CIP) and catching frequency (CF). CIP was calculated as the time between the introductions of the female to the occurrence of first male catching a female rat. CF was observed as the total number of males catching a female rat, heterosexual mounting, or cunnilingus action within $30 \mathrm{~min}$.

2.6. Determination of Relative Reproductive Organ Weight. The absolute weights of the testes and epididymides were weighed before being fixed in the polyformaldehyde. Sample weights relative to body weights were calculated as $\mathrm{g} / \mathrm{g}$ body weight.

2.7. Determination of GnRH, LH, FSH, or Testosterone in the Serum. Serum GnRH, LH, FSH, or testosterone levels were measured by ELISA according to the manufacturers' instructions and expressed as ng/L. The optical density was read using a spectrophotometer (Bio-Tek ELx 800, USA) at wavelength $450 \mathrm{~nm}$.

2.8. Histopathological Examination of Testis and Epididymis. After fixation, testis and epididymis were paraffin embedded and cut at $20 \mu \mathrm{m}$ thickness for subsequent haematoxylin and eosin ( $\mathrm{HE})$ staining. Histopathological changes in the testis and epididymis were analyzed using a light microscope (Olympus XSP-C203, Japan) at 200x magnitude by a histologist blinded to the sample treatments.

2.9. Detection of $\mathrm{G} n \mathrm{RH}$ Protein Expression by Immunohistochemistry. Dual labeling immunofluorescence staining was used to determine the expression of $\mathrm{GnRH}$. Briefly, the hypothalamic tissues were soaked in 30\% sucrose and embedded in OCT media and then cut coronally into $20 \mu \mathrm{m}$ frozen sections under $-20^{\circ} \mathrm{C}$. After being washed with $0.1 \mathrm{M}$ phosphate-buffered saline (PBS), tissue sections were blocked with $5 \%$ bovine serum albumin and $0.1 \%$ Triton X-100 for $30 \mathrm{~min}$ and then incubated overnight at $4^{\circ} \mathrm{C}$ with $20 \mu \mathrm{L}$ rabbit polyclonal anti-GnRH (1:500 dilutions). Sections were washed and incubated with $20 \mu \mathrm{L}$ donkey anti-rabbit fluorescence (1: 200 dilutions) for $45 \mathrm{~min}$ at room temperature. Sections were further washed and incubated with $5 \mu \mathrm{g} / \mathrm{mL}$ DAPI
$20 \mu \mathrm{L}$ solutions for $5 \mathrm{~min}$. The double stained sections were viewed under LEICA TCS SP5 confocal microscope (Leica Biosystems, Germany). For control purposes, the anti-GnRH was omitted. The presence of positive expression of $\mathrm{GnRH}$ was determined using the Leica LAS AF Lite software (Leica Biosystems, Germany). Six fields of view per section were randomly observed. The percentage of positive expression of $\mathrm{GnRH}$ was determined by counting the number of positive expressions of $\mathrm{GnRH}$ and divided by total number of $\mathrm{GnRH}$.

2.10. Data Analysis. Normally distributed continuous data were expressed as mean \pm standard deviation (SD). Differences between groups were determined using one-way analysis of variance (ANOVA) followed by LSD's $t$-test using SPSS software version 20.0. A $P$ value less than 0.05 was considered statistically significant.

\section{Results}

3.1. Effects of Different Parts of Aqueous Extract on CIP and CF. As shown in Figure 2(a), significant increases in the CIP were observed in the microwave exposure model compared with normal control (38.1667 \pm 4.8751 versus $26.500 \pm$ $3.0166 \mathrm{sec} ; P<0.05)$. Treatment with water layer fraction of aqueous extract $40 \mathrm{~g} / \mathrm{kg}$ decreased CIP compared with the microwave exposure model group $(32.500 \pm 4.1833$ versus $38.1667 \pm 4.8751 \mathrm{sec} ; P<0.05)$. There was no statistically significant difference in CIP (38.1667 \pm 3.37145 versus 39.1667 $\pm 3.1885 \mathrm{sec}, P>0.05$ ) between ethyl acetate layer fraction of aqueous extract $40 \mathrm{~g} / \mathrm{kg}$ and microwave exposure group.

As shown in Figure 2(b), CF of the microwave exposure group was significantly lower compared with the normal control group (32.6667 \pm 4.1793 versus $49.6667 \pm 6.4705$ times, $P<0.05)$. Treatment with water layer fraction of aqueous extract $40 \mathrm{~g} / \mathrm{kg}$ showed a trend to increase CF compared with the microwave exposure group $(38.0000 \pm 4.0497$ versus $32.6667 \pm 4.1793$ times, $P>0.05)$. However, there were no obvious changes in CF between ethyl acetate layer fraction of aqueous extract $40 \mathrm{~g} / \mathrm{kg}$ and microwave exposure group.

3.2. Relative Reproductive Organ Weight. As shown in Figures 3(a) and 3(b), significant decreases in the testis weight to body weight ratio and epididymis weight to body weight ratio were observed in the microwave exposure model compared with the normal control (all $P<0.05$ ). Treatment with water layer fraction of aqueous extract $40 \mathrm{~g} / \mathrm{kg}$ significantly increased testis-body weight ratio and epididymis-body weight ratio compared with those of the microwave exposure group $(P<$ $0.05)$. However, no significant changes were observed in the reproductive organ to body weight ratio in the ethyl acetate layer fraction of aqueous extract $40 \mathrm{~g} / \mathrm{kg}$ group.

3.3. Changes of Serum Levels of GnRH, FSH, LH, and Testosterone. As shown in Figure 4(a), significant decreases in serum GnRH levels were observed in the microwave exposure model compared with the normal control $(1.5903 \pm$ 0.0626 versus $1.6838 \pm 0.0603 \mathrm{ng} / \mathrm{L} ; P<0.05)$. Treatment with water layer fraction of aqueous extract $40 \mathrm{~g} / \mathrm{kg}$ significantly decreased serum $\mathrm{GnRH}$ levels compared with the microwave 


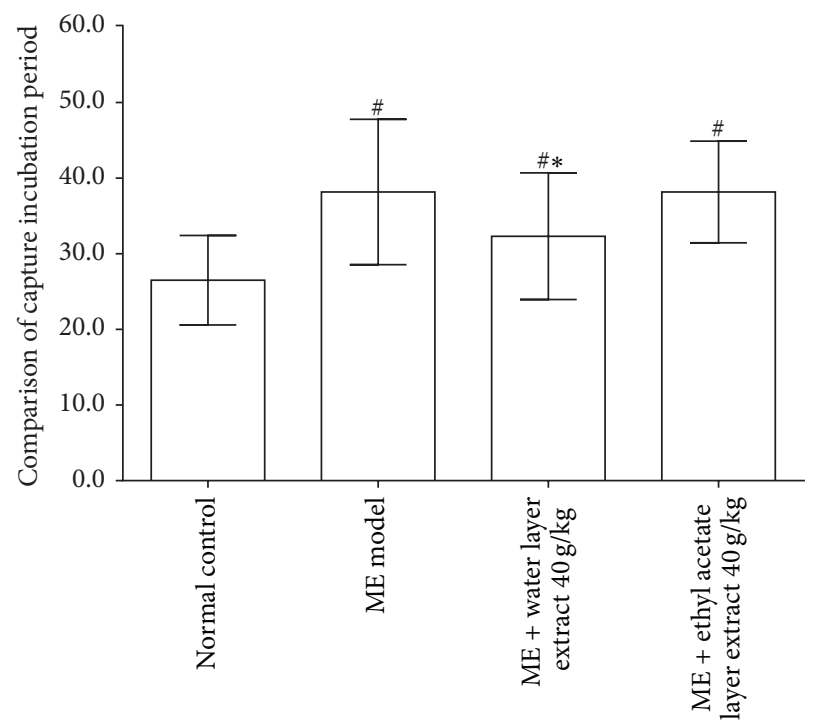

(a)

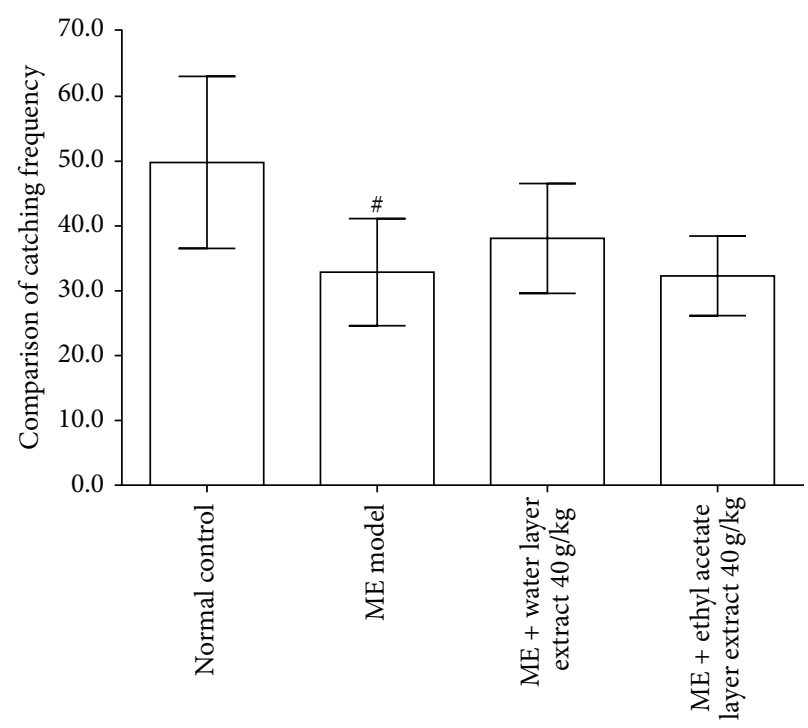

(b)

FIGURE 2: Effects of different parts of aqueous extract on capture incubation period (a) and catching frequency (b). Compared with the microwave exposure model group, water layer fraction of aqueous extract $40 \mathrm{~g} / \mathrm{kg}$ treated rats showed a decreased capture incubation period and an increased catching frequency (all $P<0.05$ ). Above changes were not observed in the ethyl acetate layer fraction of aqueous extract $40 \mathrm{~g} / \mathrm{kg}$ treated rats. Values are expressed as mean $\pm \mathrm{SD}(n=6) .{ }^{*} P<0.05$, versus normal control group. ${ }^{*} P<0.05$, versus microwave exposure model group. $\mathrm{ME}=$ microwave exposure.

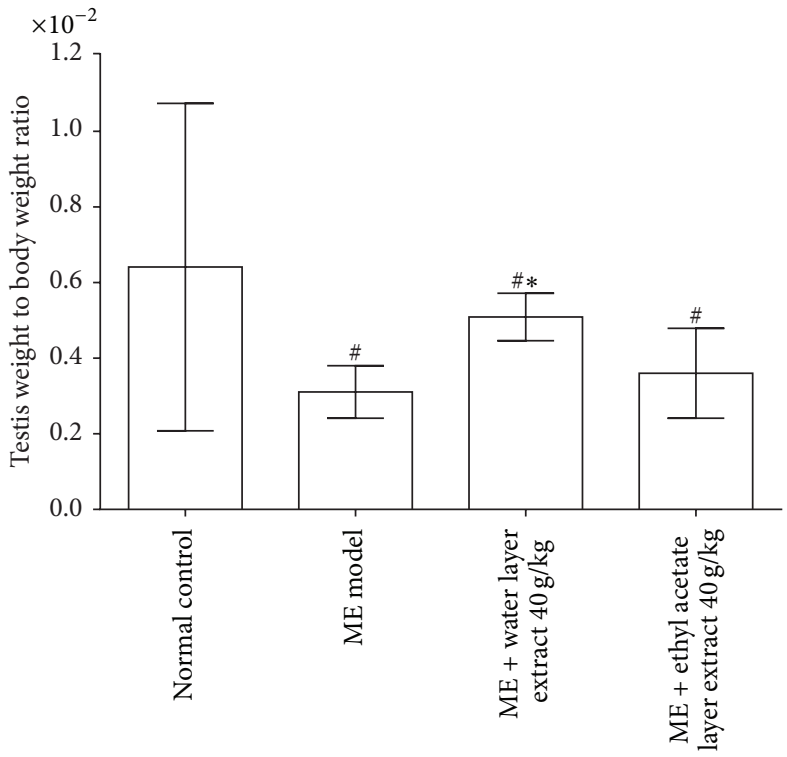

(a)

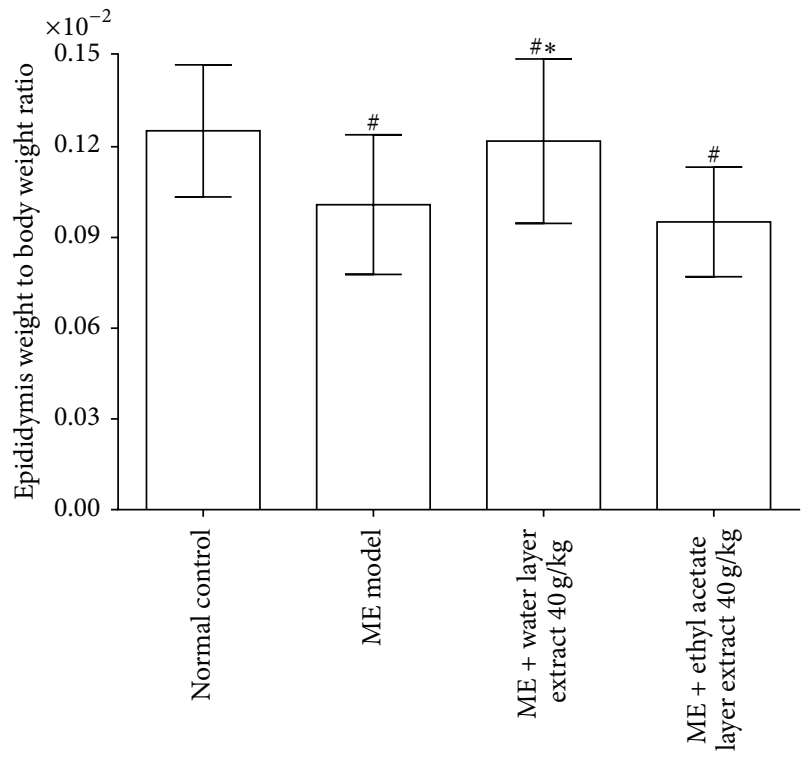

(b)

FIGURE 3: Effects of different parts of aqueous extract on testis to body weight ratio (a) and epididymis to body weight ratio (b). Compared with the microwave exposure model group, water layer fraction of aqueous extract $40 \mathrm{~g} / \mathrm{kg}$ treated rats showed an increased testis to body weight ratio and epididymis to body weight ratio (all $P<0.05$ ), but not compared with the ethyl acetate layer fraction of aqueous extract $40 \mathrm{~g} / \mathrm{kg}$ treated rats. Values are expressed as mean $\pm \mathrm{SD}(n=6) .{ }^{\#} P<0.05$, versus normal control group. ${ }^{*} P<0.05$, versus microwave exposure model group. $\mathrm{ME}=$ microwave exposure.

exposure model group $(1.4987 \pm 0.0739$ versus $1.5903 \pm$ $0.0626 \mathrm{ng} / \mathrm{L} ; P<0.05)$. As shown in Figure 4(b), treatment with water layer fraction of aqueous extract $40 \mathrm{~g} / \mathrm{kg}$ did not significantly affect serum FSH levels compared with the microwave exposure model group $(P>0.05)$. As shown in Figures 4(c) and 4(d), compared with the microwave exposure model group, water layer fraction of aqueous extract $40 \mathrm{~g} / \mathrm{kg}$ treatment was associated with a decrease in serum LH levels $(2.8118 \pm 1.0280$ versus $4.5915 \pm 0.5609 \mathrm{ng} / \mathrm{L} ; P<0.05)$ and an increase in serum testosterone levels $(9.8690 \pm 2.5188$ 


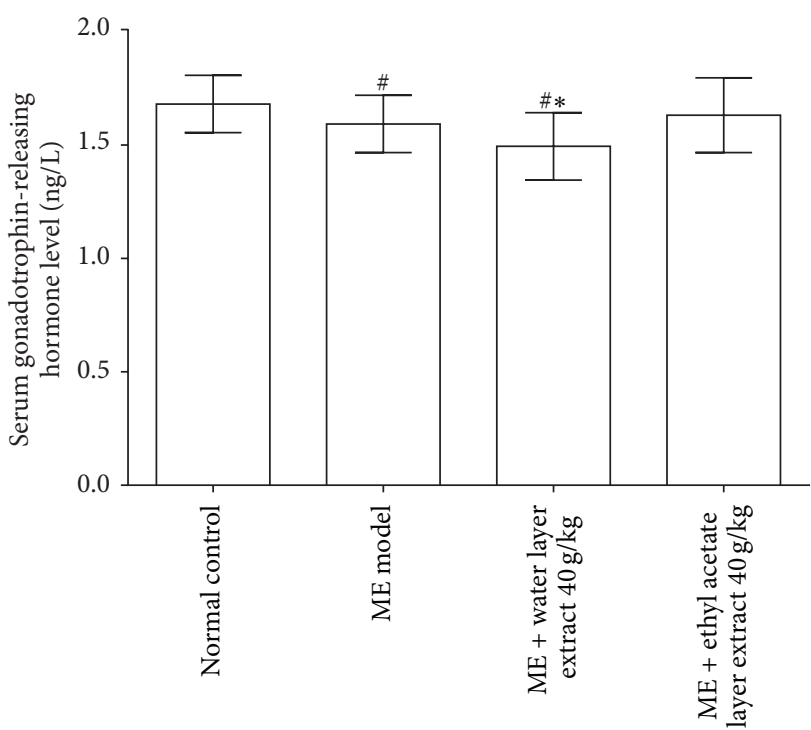

(a)

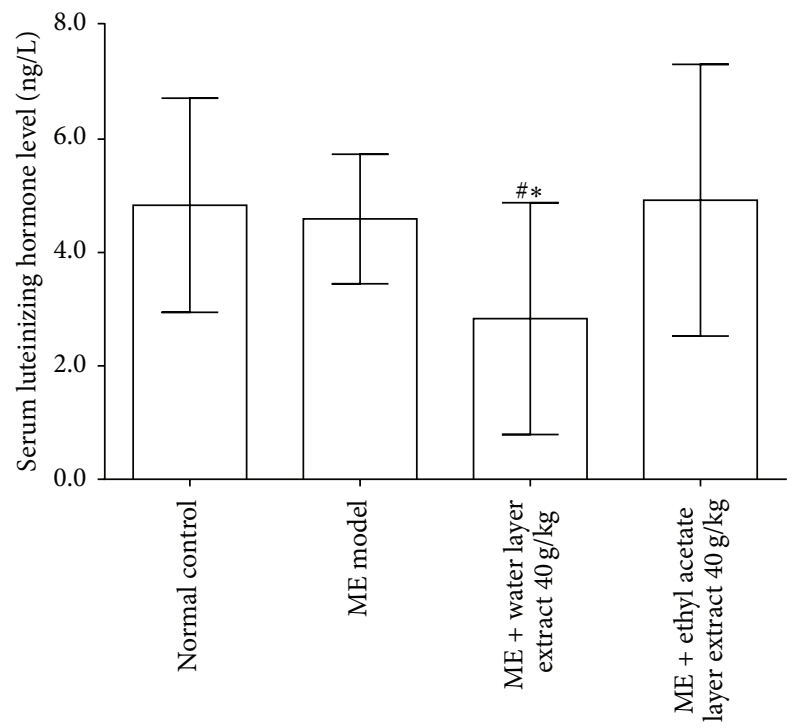

(c)

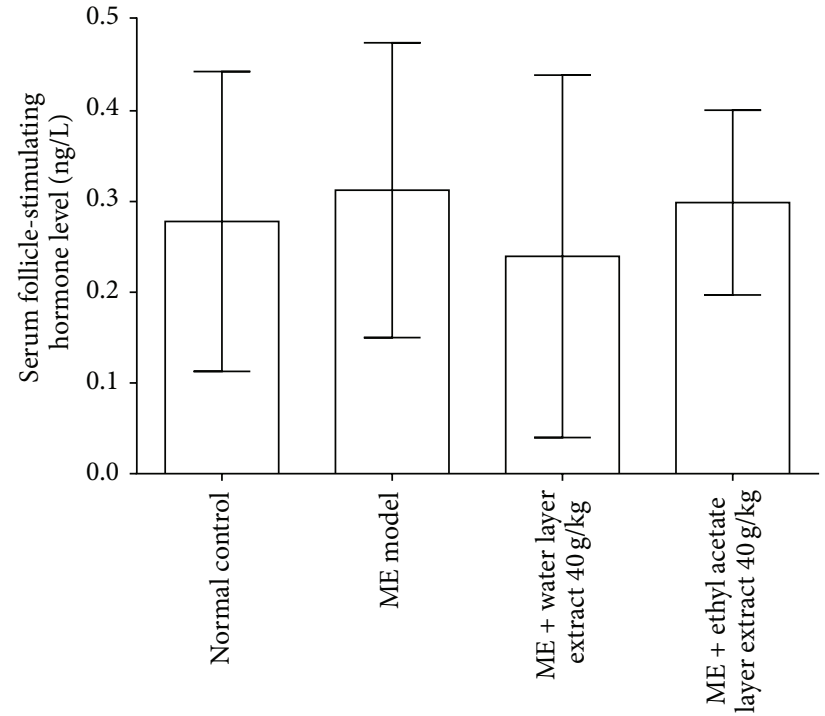

(b)

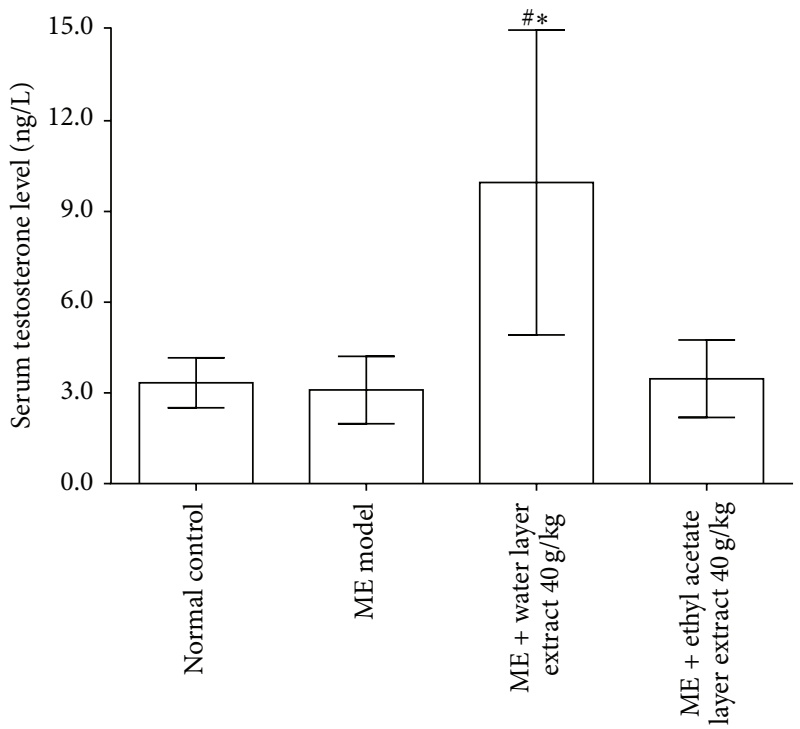

(d)

FIGURE 4: Effects of different parts of aqueous extract on serum levels of gonadotrophin-releasing hormone (a), follicle-stimulating hormone (b), luteinizing hormone (c), and testosterone (d). Values are expressed as mean $\pm \mathrm{SD}(n=6) .{ }^{\#} P<0.05$, versus normal control group. ${ }^{*} P<0.05$, versus microwave exposure model group. $\mathrm{ME}=$ microwave exposure.

versus $3.1262 \pm 0.55885 \mathrm{ng} / \mathrm{L}, P<0.05)$. However, ethyl acetate layer fraction of aqueous extract $40 \mathrm{~g} / \mathrm{kg}$ did not affect serum levels of GnRH, FSH, LH, and testosterone.

3.4. Histopathological Changes of Testis and Epididymis. Light microscopy of testicular sections taken from normal control testis showed normal seminiferous tubules containing developing sperm cells at different stages and interstitial tissue (Figure 5(a)). Testicular sections from microwave exposure model rats revealed various degrees of disorganization, degeneration, and reduction in germinal cells (Figure 5(b)). Testicular tissues from rats treated with a water layer fraction of aqueous extract $40 \mathrm{~g} / \mathrm{kg}$ showed a well-preserved testicular histology (Figure 5(c)). In contrast, testicular sections in the ethyl acetate layer fraction of aqueous extract $40 \mathrm{~g} / \mathrm{kg}$ group revealed various degrees of degeneration or necrosis of spermatogonia/spermatocyte (Figure 5(d)).

The epididymal tissues in normal control rats showed a normal architecture, characterized by an abundance of normal sperms in the epididymal ducts (Figure 5(e)). However, epididymal tissues in the microwave exposure group showed some exfoliated cells, cell debris, without sperm in the epididymal duct (Figure 5(f)). These findings were attenuated in the water layer fraction of aqueous extract $40 \mathrm{~g} / \mathrm{kg}$ group and presented a great quantity of sperms (Figure $5(\mathrm{~g})$ ) while epididymal tissues in the ethyl acetate layer fraction of 


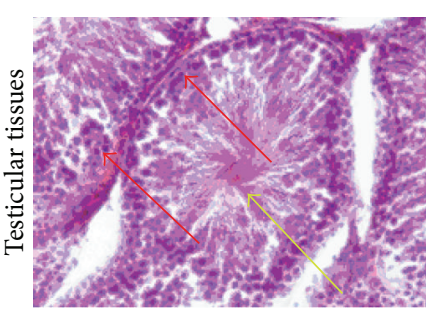

(a)

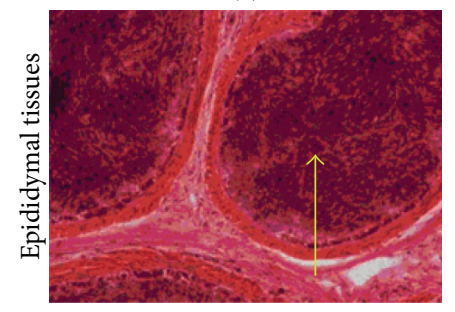

Normal control

(e)

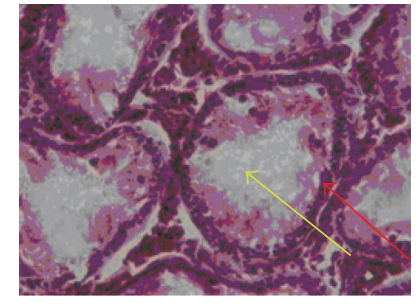

(b)

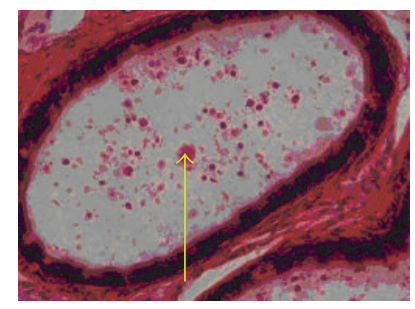

ME model

(f)

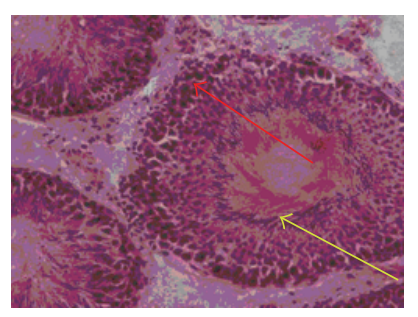

(c)

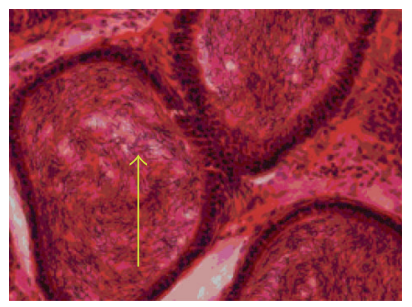

$\mathrm{ME}$ + water layer extract $40 \mathrm{~g} / \mathrm{kg}$

(g)

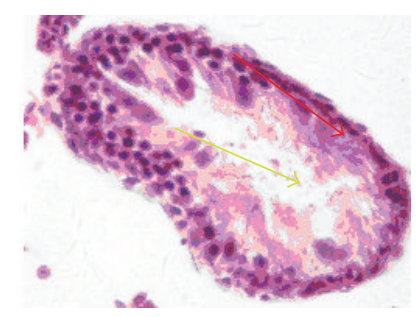

(d)

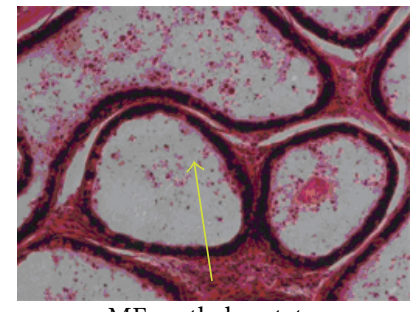

$\mathrm{ME}+$ ethyl acetate

layer extract $40 \mathrm{~g} / \mathrm{kg}$

(h)

FIGURE 5: Effects of different parts of aqueous extract on histopathological changes in testis and epididymis. In testicular H\&E staining (Figures 5(a)-5(d)), the normal control group showed well-arranged spermatogenic cell series (red arrow) and an abundance of sperms in the seminiferous tubule (yellow arrow) at 200x magnification; the microwave exposure model group showed wide spaces between each seminiferous tubule, a significant decrease in the seminiferous tubule diameter, fewer sperms in seminiferous tubule (yellow arrow), degeneration of spermatocyte/spermatogonia, and cell debris in ducts (red arrow) at 200x magnification; the water layer fraction of aqueous extract $40 \mathrm{~g} / \mathrm{kg}$ group showed complete spermatogenic cell series and almost normal sperm counts at 200x magnification; the ethyl acetate layer fraction of aqueous extract $40 \mathrm{~g} / \mathrm{kg}$ group showed necrosis and desquamate spermatogenic cells at 200x magnification. In epididymal H\&E staining (Figures 5(e)-5(h) at 200x magnification), the normal control group showed an abundance of normal sperms in the epididymal ducts (yellow arrow); the microwave exposure model group showed no sperms except for many fallen spermatogenic cells or cell debris in the ducts (yellow arrow); the water layer fraction of aqueous extract $40 \mathrm{~g} / \mathrm{kg}$ group showed increased quantity of sperms and rare exfoliated cells in the epididymal ducts (yellow arrow); the ethyl acetate layer fraction of aqueous extract $40 \mathrm{~g} / \mathrm{kg}$ group showed only many exfoliated cells and no sperms in the epididymal ducts (yellow arrow).

aqueous extract $40 \mathrm{~g} / \mathrm{kg}$ group rats did not show obvious improvement, characterized by only a few exfoliated cells without sperms in the epididymal ducts (Figure 5(h)).

3.5. Immunohistochemical Analysis of GnRH. Dual labeling immunofluorescence staining of hypothalamic sections revealed GnRH distribution in the arcuate nucleus of the hypothalamus below the third ventricle (Figures 6(a)-6(i)). The positive immunofluorescence density of GnRH was decreased in the microwave exposure group compared with the normal control group. The positive immunofluorescence density of GnRH was obviously decreased in the water layer fraction of aqueous extract treated rats but not in the ethyl acetate layer fraction of aqueous extract treated rats.

As shown in Figure 7, despite the finding that microwave exposure showed some trend towards decreased GnRH protein expression, there was no statistically significant difference in the positive GnRH immunofluorescence density compared with the normal control group $(0.6833 \pm 0.0756$ versus $0.7605 \pm 0.1035 ; P>0.05)$. Treatment with water layer fraction of aqueous extract $40 \mathrm{~g} / \mathrm{kg}$ significantly decreased positive GnRH immunofluorescence density compared with the microwave exposure group $(0.5675 \pm 0.0565$ versus $0.6833 \pm 0.0756 ; P<0.05)$. Ethyl acetate layer fraction of aqueous extract $40 \mathrm{~g} / \mathrm{kg}$ did not affect positive $\mathrm{GnRH}$ immunofluorescence density in the hypothalamus.

\section{Discussion}

In this study, we established a reproductive impairment rat model by exposure to $900 \mathrm{MHz}$ microwave with microwave signal generator at $218 \mu \mathrm{m} / \mathrm{cm}^{2}$ radiation densities for consecutive 10 days. Male rat reproductive impairment induced by microwaves was confirmed by various degrees of degeneration or decreased number of spermatogonia/spermatocyte upon histological examination, reduction in the weight of testis and epididymis, and serum testosterone levels, as well as lower sexual performance.

Treatment with water layer fraction of aqueous extract derived from Morinda officinalis F. C. How $40 \mathrm{~g} / \mathrm{kg}$ improved sexual performance, characterized by decreased CIP; increased the weight of reproductive organs; attenuated histopathological changes of testis and epididymis; increased serum testosterone; decreased serum LH and GnRH levels; and decreased $\mathrm{GnRH}$ positive immunofluorescence density. Together these findings suggest that water layer fraction of aqueous extract from Morinda officinalis F. C. How in the doses used in this study can ameliorate microwave-reduced hypothalamic-pituitary-testicular impairment. 
(A)

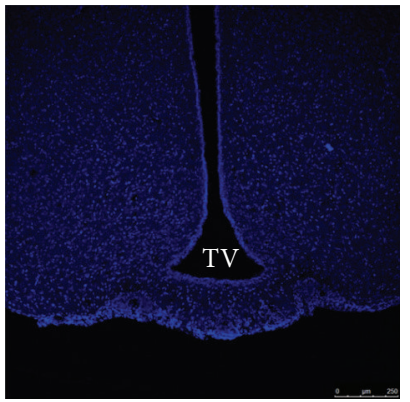

(a)

(B)

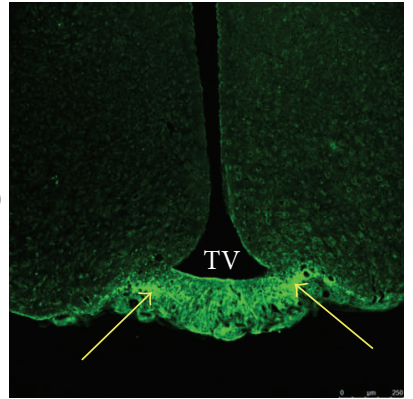

(e)

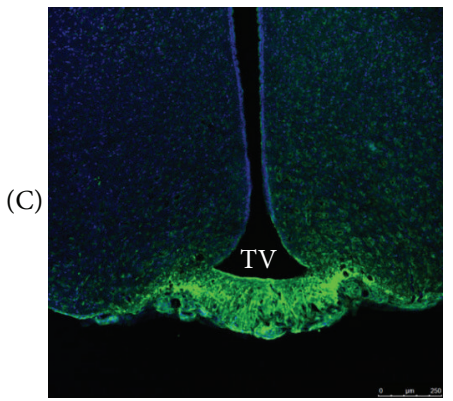

Normal control

(i)

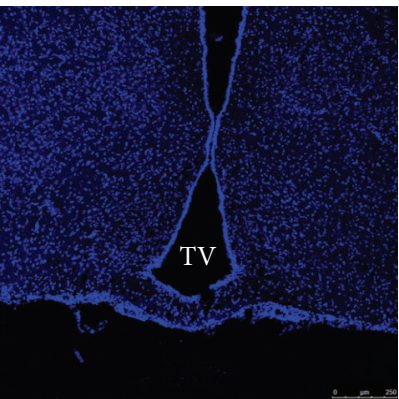

(b)

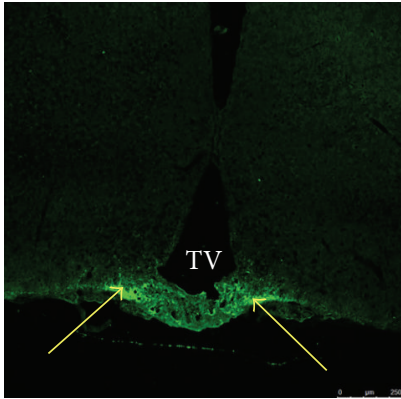

(f)

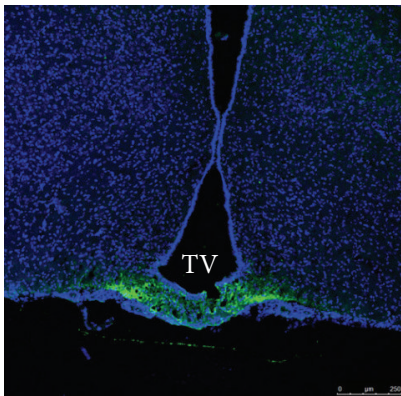

ME model

(j)

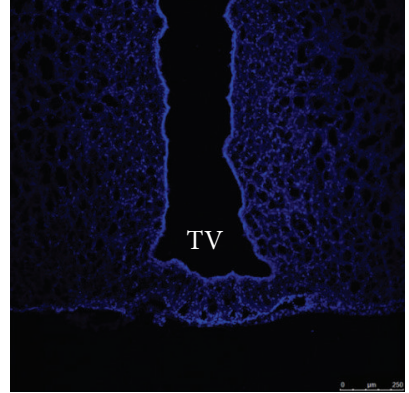

(c)

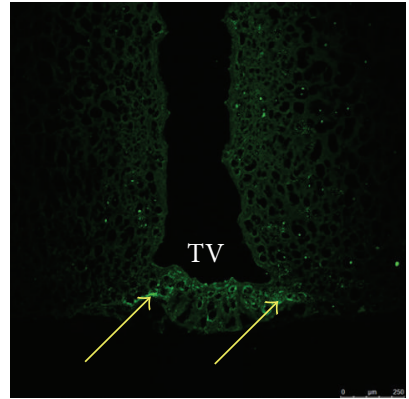

(g)

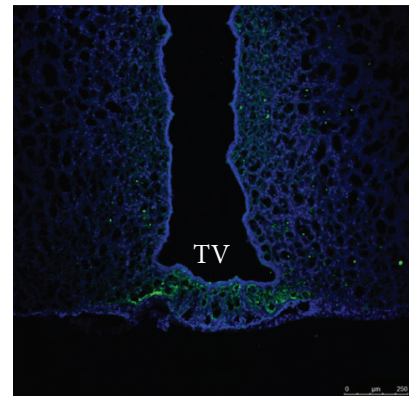

$\mathrm{ME}+$ water layer extract $40 \mathrm{~g} / \mathrm{kg}$

(k)

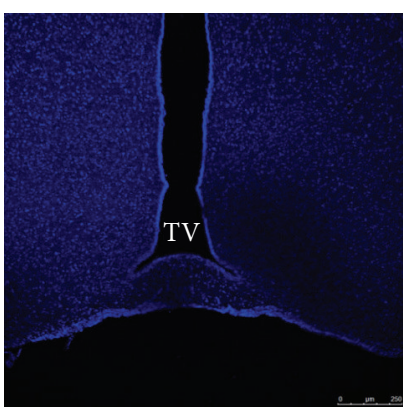

(d)

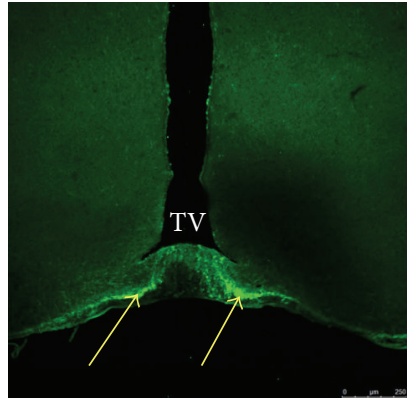

(h)

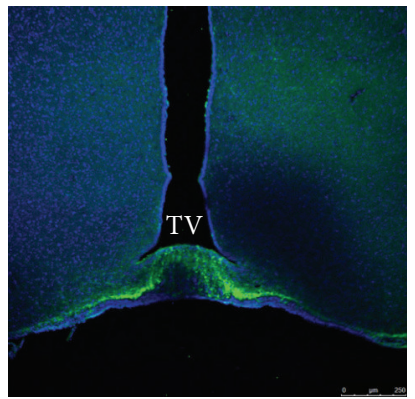

$\mathrm{ME}+$ ethyl acetate

layer extract $40 \mathrm{~g} / \mathrm{kg}$

(1)

FIGURE 6: Representative coronal images of the arcuate nucleus of the hypothalamus showing immunohistochemical double labeling for GnRH/DAPI. Photomicrographs of DAPI ((a)-(d)) and GnRH ((e)-(h)) and merged images of DAPI and GnRH ((i)-(l)). The yellow arrow represents positive GnRH expression. Treatment with water layer fraction of aqueous extract $40 \mathrm{~g} / \mathrm{kg}$ significantly decreased the $\mathrm{GnRH}$ fluorescence intensity of the hypothalamus compared with the microwave exposure group. $\mathrm{GnRH}=$ gonadotrophin-releasing hormone; TV $=$ third ventricle. DAPI $=4,6$-diamidino-2-phenylindole. Scale bar $=250 \mu \mathrm{m}$.

Male reproductive function is a complex process requiring high energy. Testis is the central organ of the male germline regulated by the hypothalamus and pituitary through different feedback regulation mechanisms. Regulatory mechanisms are controlled mainly through $\mathrm{GnRH}$, FSH, and LH acting on the hypothalamus-pituitary-testis axis. The hypothalamus monitors reproductive state through neurons that release GnRH. GnRH promotes LH and FSH release through the anterior pituitary. $\mathrm{LH}$ acts on testicular interstitial cells, promoting secretion of testosterone. FSH is responsible for the activation of the seminiferous tubules maintaining the production of sperm. Therefore, hypothalamic injury indirectly leads to male reproductive impairment and further results in injury of reproductive organs. Meanwhile, reproductive organ damage can induce disorder of hypothalamic-pituitary-testicular axis through negative feedback mechanisms [19].

The possible adverse effects of exposure to cell phone microwaves on male reproductive disorder have been a hot topic. Evidence from human and animal studies suggests a possible link between cell phone use and male infertility [20]. Mobile phones are often carried in trouser pockets or belt clip near the reproductive organs in men. Carrying a mobile phone near the testes may result in decreased testosterone or sperm production in men. Findings from our study were in line with many studies. Ozguner et al. [21] indicated that the diameter of seminiferous tubules and the mean height of the germinal epithelium were significantly decreased after $900 \mathrm{MHz}$ microwave exposure in male rats. Ghanbari et al. [22] found that exposure to cell phone waves $950 \mathrm{MHz}$ for 14 


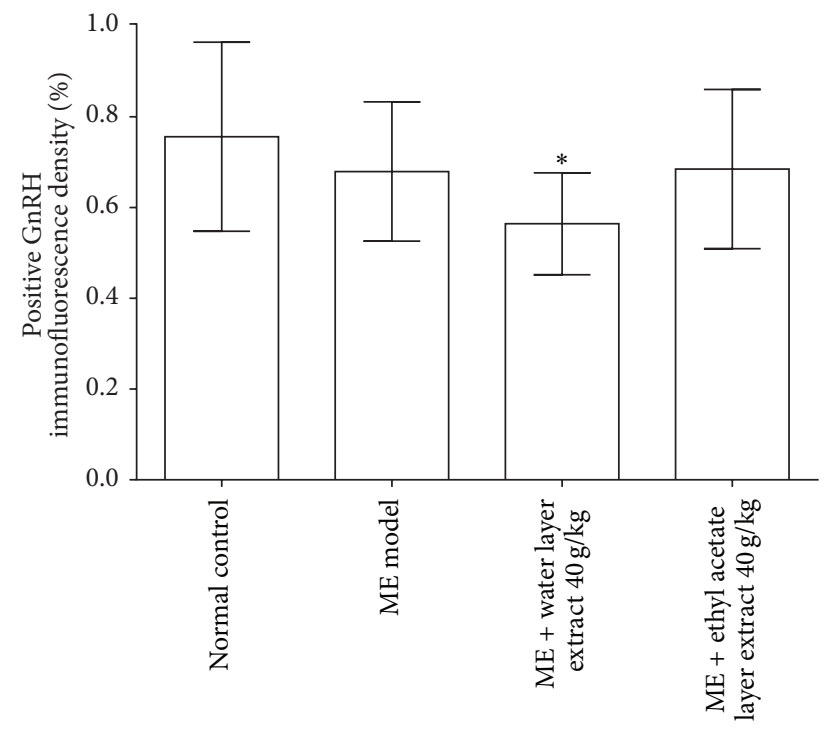

Figure 7: Percentage of positive GnRH immunofluorescence density. Values are expressed as mean $\pm \mathrm{SD}(n=6) .{ }^{\#} P<0.05$, versus normal control group. ${ }^{*} P<0.05$, versus microwave exposure model group. $\mathrm{ME}=$ microwave exposure $\mathrm{GnRH}=$ gonadotrophinreleasing hormone.

days decreased sperm viability and motility in rats. Meo et al. [23] reported that exposure to mobile phone radiation for $60 \mathrm{~min} /$ day for up to 3 months significantly reduced serum testosterone levels. More recently, Odacı and Özyılmaz [24] showed that exposure to a $900 \mathrm{MHz}$ electromagnetic field for $1 \mathrm{~h}$ /day over 30 days caused bad outcomes in adult rat testicular morphology and biochemistry. In human studies, an obvious decrease in sperm motility in semen samples exposed to a $900 \mathrm{MHz}$ cell phone for $5 \mathrm{~min}$ was observed among men [25]. Mobile phone radiation exposure was associated with DNA fragmentation and decreased sperm motility in healthy men $[26,27]$. In addition, cell phone use in men was associated with decreased sperm count and viability $[28,29]$, which may contribute to male infertility. In contrast to above studies and our study, few studies [30, 31] have reported no adverse effects of $900 \mathrm{MHz}$ microwave exposure on testicular function or structure and epididymal sperm counts in male rats.

Testosterone is primarily a male hormone and reduction in testosterone level may result in reproductive disorder. Male reproductive function is regulated by precise and coordinated secretion of GnRH, LH, FSH, and testosterone. Testes are responsible for the production of spermatozoa and synthesis and release of testosterone. In the current study, after water layer fraction of aqueous extract $40 \mathrm{~g} / \mathrm{kg}$ treatment for 14 days, serum levels of testosterone significantly increased and LH decreased significantly compared with the values found in microwave exposure model rats. However, serum levels of LH and FSH were differentially modified, which indicated that water layer fraction of aqueous extract differentially affects both hypothalamic and pituitary levels in the hypothalamicpituitary-testicular axis. The increase in serum testosterone levels observed after water layer fraction of aqueous extract treatment may reflect direct effects on the testis. Testosterone acts on the seminiferous tubules to initiate and maintain spermatogenesis [32]. Our study was supported by Liu et al. who indicated that treatment with water decoction of Morinda officinalis F. C. How $20 \mathrm{~g} / \mathrm{kg}$ significantly increased serum testosterone levels compared with microwave exposure model rats [33]. Histopathological analysis demonstrated a significant increase in the epididymal sperm count of rats treated with a water layer fraction of aqueous extract for 14 days along with higher serum testosterone levels. In addition, increment in the weight of testis and epididymis may be attributed to increased secretory activity of these organs.

The positive GnRH immunofluorescence density of the arcuate nucleus in the hypothalamus was significantly decreased in the water layer fraction of aqueous extract treated rats. Meanwhile, serum levels of $\mathrm{GnRH}$ were also reduced. These results might be explained by the water layer fraction of aqueous extract directly increasing testosterone level and indirectly inhibiting GnRH synthesis and release via a feedback loop system. Taken together, the protective effect of Morinda officinalis F. C. How on reproductive impairment is mainly located at the testicular and epididymal level while changes of $\mathrm{GnRH}$, LH, or FSH might be regulated by gonadal hormone feedback loop system involving the anterior pituitary and hypothalamus and testis.

Morinda officinalis How, as a Kidney-Yang tonic agent, has been used to enhance sexual functions for thousands of years. Morinda officinalis F. C. How decoction could decrease sperm deformity rate in male mice via acting on spermatogonia and primary spermatocytes [34]. Bajijiasu, isolated from the roots of Morinda officinalis F. C. How, either enhanced the sexual function of normal mice or increased testosterone levels and histopathological findings in the testis [35]. Morinda officinalis F. C. How oligosaccharides promoted the growth of the testis and increased production of sperm by the testis [36]. These findings suggest that crude Morinda officinalis F. C. How and its extract had therapeutic potential for male infertility.

Oxidative stress, a cellular or physiological condition, plays an important role in male infertility. A possible link between the biological systems and microwave radiation is oxidative stress. Microwave radiation is responsible for the generation of free radicals and reactive oxygen species, which might be a possible link between male reproductive impairments and microwave exposure. Nonthermal effects of cell phones lead to oxidative stress on the male reproductive system through increased generation of seminal reactive oxygen species and reduction in antioxidant enzymes [37]. The extract of Morinda officinalis has shown antioxidant properties $[38,39]$. Acidic polysaccharide from Morinda officinalis F. C. How may partly contribute to its antioxidant activity [40]. Morinda officinalis F. C. How protected functions of cultured mouse TM3 Leydig cells from hydrogen peroxideinduced oxidative stress in vitro [41]. Taken together, antioxidant properties of Morinda officinalis F. C. How may be one of the possible mechanisms against microwave-induced reproductive impairments.

There were many limitations in the current study. First, antioxidant treatment could be beneficial in preventing or 
decreasing some complications of microwave radiation [42, 43]; however, whether the protective effects of water layer fraction of aqueous extract of Morinda officinalis F. C. How occur via antioxidant property needs to be further studied. Second, we did not investigate the effects of water layer fraction of aqueous extraction impairment on sperm. Additional future studies should be focused on the assessment of the protective effects on sperm injury both in vitro and in vivo. Finally, this study cannot determine the dose-effect of aqueous extract of Morinda officinalis F. C. How. A future study is suggested to investigate the dose-effect of aqueous extract of Morinda officinalis F. C. How.

In conclusion, the present study demonstrated that a water layer fraction of aqueous extract derived from Morinda officinalis F. C. How had protective effects against hypothalamus-pituitary-testis axis impairment induced by microwave radiation in male rats. This study thus provided some evidence that Morinda officinalis F. C. How might be a promising agent for treatment of male reproductive impairment induced by microwave radiation. However, detailed molecular mechanisms of action and key active compounds of Morinda officinalis F. C. How still need to be further investigated.

\section{Conflict of Interests}

The authors have no conflict of interests to declare.

\section{Acknowledgments}

This work was supported by Fujian Provincial Natural Science Foundation of China (Grant no. 2014J01330) and the Key Technology Plan Program of Fujian Provincial Science and Technology Department of China (Grant no. 2012Y0032).

\section{References}

[1] P. N. Schlegel, "Evaluation of male infertility," Minerva Ginecologica, vol. 61, no. 4, pp. 261-283, 2009.

[2] S. Wilkes, D. J. Chinn, A. Murdoch, and G. Rubin, "Epidemiology and management of infertility: a population-based study in UK primary care," Family Practice, vol. 26, no. 4, pp. 269-274, 2009.

[3] A. Agarwal, A. Singh, A. Hamada, and K. Kesari, "Cell phones and male infertility: a review of recent innovations in technology and consequences," The International Brazilian Journal of Urology, vol. 37, no. 4, pp. 432-454, 2011.

[4] N. Kang, X.-J. Shang, and Y.-F. Huang, "Impact of cell phone radiation on male reproduction," Zhonghua Nan Ke Xue, vol. 16, no. 11, pp. 1027-1030, 2010.

[5] S. La Vignera, R. A. Condorelli, E. Vicari, R. D’Agata, and A. E. Calogero, "Effects of the exposure to mobile phones on male reproduction: a review of the literature," Journal of Andrology, vol. 33, no. 3, pp. 350-356, 2012.

[6] J. A. Adams, T. S. Galloway, D. Mondal, S. C. Esteves, and F. Mathews, "Effect of mobile telephones on sperm quality: a systematic review and meta-analysis," Environment International, vol. 70, pp. 106-112, 2014.

[7] R. M. Perrett and C. A. McArdle, "Molecular mechanisms of gonadotropin-releasing hormone signaling: integrating cyclic nucleotides into the network," Frontiers in Endocrinology, vol. 4, article 180, Article ID Article 180, 2013.

[8] S. M. van Anders, K. L. Goldey, and S. N. Bell, "Measurement of testosterone in human sexuality research: methodological considerations," Archives of Sexual Behavior, vol. 43, no. 2, pp. 231-250, 2014.

[9] A. Agarwal, F. Deepinder, R. K. Sharma, G. Ranga, and J. Li, "Effect of cell phone usage on semen analysis in men attending infertility clinic: an observational study," Fertility and Sterility, vol. 89, no. 1, pp. 124-128, 2008.

[10] O. F. Sonmez, E. Odaci, O. Bas, and S. Kaplan, "Purkinje cell number decreases in the adult female rat cerebellum following exposure to $900 \mathrm{MHz}$ electromagnetic field," Brain Research, vol. 1356, pp. 95-101, 2010.

[11] T. Jorge-Mora, M. J. Misa-Agustiño, J. A. Rodríguez-González, F. J. Jorge-Barreiro, F. J. Ares-Pena, and E. López-Martín, "The effects of single and repeated exposure to $2.45 \mathrm{GHz}$ radiofrequency fields on c-fos protein expression in the paraventricular nucleus of rat hypothalamus," Neurochemical Research, vol. 36, no. 12, pp. 2322-2332, 2011.

[12] L. J. Challis, "Mechanisms for interaction between RF fields and biological tissue," Bioelectromagnetics, vol. 26, supplement 7, pp. S98-S106, 2005.

[13] K. K. Kesari, S. Kumar, J. Nirala, M. H. Siddiqui, and J. Behari, "Biophysical evaluation of radiofrequency electromagnetic field effects on male reproductive pattern," Cell Biochemistry and Biophysics, vol. 65, no. 2, pp. 85-96, 2013.

[14] W. Zhang, S. P. Kang, Q. R. Cheng et al., "Effect of Morinda officinalis on male rats' spermatogenic dysfunction induced by microwave," Anatomy Research International, vol. 32, no. 5, pp. 338-340, 2010.

[15] F.-J. Wang, W. Wang, R. Li, B. Song, Y.-H. Zhang, and Y.-X. Zhou, "Morinda officialis how extract improves microwaveinduced reproductive impairment in male rats," Zhonghua Nan Ke Xue, vol. 19, no. 4, pp. 340-345, 2013.

[16] R. Li, L. C. Liu, G. Wang, and W. Wang, "Effect of Morinda officinalis on microwave-induced reproductive disorder in male rats," Guangdong Medical Journal, vol. 36, no. 1, pp. 58-60, 2015.

[17] S. Y. Zheng and J. Chen, "Progress of the constituents of Morinda officinalis and its pharmacological action," World Journal of Integrated Traditional and Western Medicine, vol. 7, no. 9, pp. 823-826, 2012.

[18] N. Cui, J. Shi, H. Q. Jing, and T. Z. Jia, "Screening the effective components and mechanism of Morinda officinalis on tonifying kidney and noursing Yang," Chinese Traditional Patent Medicine, vol. 35, no. 10, pp. 2256-2258, 2013.

[19] A. C. Hackney, A. W. Moore, and K. K. Brownlee, "Testosterone and endurance exercise: development of the 'exercisehypogonadal male condition,' Acta Physiologica Hungarica, vol. 92, no. 2, pp. 121-137, 2005.

[20] Z. O. Merhi, "Challenging cell phone impact on reproduction: a review," Journal of Assisted Reproduction and Genetics, vol. 29, no. 4, pp. 293-297, 2012.

[21] M. Ozguner, A. Koyu, G. Cesur et al., "Biological and morphological effects on the reproductive organ of rats after exposure to electromagnetic field," Saudi Medical Journal, vol. 26, no. 3, pp. 405-410, 2005.

[22] M. Ghanbari, S. B. Mortazavi, A. Khavanin, and M. Khazaei, "The effects of cell phone waves (900 MHz-GSM Band) on sperm parameters and total antioxidant capacity in rats," International Journal of Fertility and Sterility, vol. 7, no. 1, pp. 21-28, 2013. 
[23] S. A. Meo, A. M. Al-Drees, S. Husain, M. M. Khan, and M. B. Imran, "Effects of mobile phone radiation on serum testosterone in Wistar albino rats," Saudi Medical Journal, vol. 31, no. 8, pp. 869-873, 2010.

[24] E. Odacı and C. Özyılmaz, "Exposure to a $900 \mathrm{MHz}$ electromagnetic field for 1 hour a day over 30 days does change the histopathology and biochemistry of the rat testis," International Journal of Radiation Biology, vol. 91, no. 7, pp. 547-554, 2015.

[25] O. Erogul, E. Oztas, I. Yildirim et al., "Effects of electromagnetic radiation from a cellular phone on human sperm motility: an in vitro study," Archives of Medical Research, vol. 37, no. 7, pp. 840843, 2006.

[26] I. Gorpinchenko, O. Nikitin, O. Banyra, and A. Shulyak, "The influence of direct mobile phone radiation on sperm quality," Central European Journal of Urology, vol. 67, no. 1, pp. 65-71, 2014.

[27] A. Zalata, A. Z. El-Samanoudy, D. Shaalan, Y. El-Baiomy, and T. Mostafa, "In vitro effect of cell phone radiation on motility, DNA fragmentation and Clusterin gene expression in human sperm," International Journal of Fertility \& Sterility, vol. 9, no. 1, pp. 129-136, 2015.

[28] T. Gutschi, B. Mohamad Al-Ali, R. Shamloul, K. Pummer, and $\mathrm{H}$. Trummer, "Impact of cell phone use on men's semen parameters," Andrologia, vol. 43, no. 5, pp. 312-316, 2011.

[29] N. Falzone, C. Huyser, F. Fourie, T. Toivo, D. Leszczynski, and D. Franken, "In vitro effect of pulsed $900 \mathrm{MHz}$ GSM radiation on mitochondrial membrane potential and motility of human spermatozoa," Bioelectromagnetics, vol. 29, no. 4, pp. 268-276, 2008.

[30] S. Dasdag, M. A. Ketani, Z. Akdag et al., "Whole-body microwave exposure emitted by cellular phones and testicular function of rats," Urological Research, vol. 27, no. 3, pp. 219-223, 1999.

[31] S. Dasdag, M. Z. Akdag, F. Aksen et al., "Whole body exposure of rats to microwaves emitted from a cell phone does not affect the testes," Bioelectromagnetics, vol. 24, no. 3, pp. 182-188, 2003.

[32] F. F. G. Rommerts, "How much androgen is required for maintenance of spermatogenesis?" Journal of Endocrinology, vol. 116, no. 1, pp. 7-9, 1988.

[33] X. Q. Liu, Y. Y. Yan, Y. B. Gao et al., "Effect of Morinda officinalis on male rats' spermatogenic dysfunction induced by microwave," Anatomy Research, vol. 35, no. 6, pp. 431-434, 2013.

[34] J. Lin, R. C. Jiang, G. M. Chen et al., "Effect of Morinda officinalis on sperm abnormality in mice," Strait Pharmaceutical Journal, vol. 7, no. 1, pp. 83-84, 1995.

[35] Z. Q. Wu, D. L. Chen, F. H. Lin et al., "Effect of bajijiasu isolated from Morinda officinalis F. C. how on sexual function in male mice and its antioxidant protection of human sperm," Journal of Ethnopharmacology, vol. 164, pp. 283-292, 2015.

[36] P. Ding, Y.-J. Liang, J. Liu, and T.-C. Yang, "Effect of Morinda officinalis oligosaccharides on sperm product in mice," Chinese Pharmaceutical Journal, vol. 43, no. 19, pp. 1467-1470, 2008.

[37] N. R. Desai, K. K. Kesari, and A. Agarwal, "Pathophysiology of cell phone radiation: oxidative stress and carcinogenesis with focus on male reproductive system," Reproductive Biology and Endocrinology, vol. 7, article 114, 2009.

[38] X. Yang, Y.-H. Zhang, C.-F. Ding, Z.-Z. Yan, and J. Du, "Extract from Morindae officinalis against oxidative injury of function to human sperm membrane," China Journal of Chinese Materia Medica, vol. 31, no. 19, pp. 1614-1617, 2006.
[39] Z. Z. Yan, X. Yang, Y. H. Zhang, C. F. Dingt, and J. Du, "Protective effect of extract from Morindae officinalis on the oxidative injury of human sperm motility," Chinese Journal of Rehabilitation Theory and Practice, vol. 12, no. 8, pp. 701-703, 2006.

[40] H. Zhang, J. Li, J. Xia, and S. Lin, "Antioxidant activity and physicochemical properties of an acidic polysaccharide from Morinda officinalis," International Journal of Biological Macromolecules, vol. 58, pp. 7-12, 2013.

[41] M.-S. Chang, W.-N. Kim, W.-M. Yang, H.-Y. Kim, J.-H. Oh, and S.-K. Park, "Cytoprotective effects of Morinda officinalis against hydrogen peroxide-induced oxidative stress in Leydig TM3 cells," Asian Journal of Andrology, vol. 10, no. 4, pp. 667674, 2008.

[42] R. Meena, K. Kumari, J. Kumar, P. Rajamani, H. N. Verma, and K. K. Kesari, "Therapeutic approaches of melatonin in microwave radiations-induced oxidative stress-mediated toxicity on male fertility pattern of wistar rats," Electromagnetic Biology and Medicine, vol. 33, no. 2, pp. 81-91, 2014.

[43] B. Oral, M. Guney, F. Ozguner et al., "Endometrial apoptosis induced by a $900-\mathrm{MHz}$ mobile phone: preventive effects of vitamins E and C," Advances in Therapy, vol. 23, no. 6, pp. 957973, 2006. 


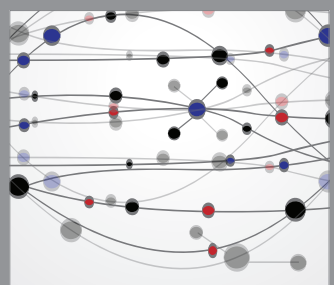

The Scientific World Journal
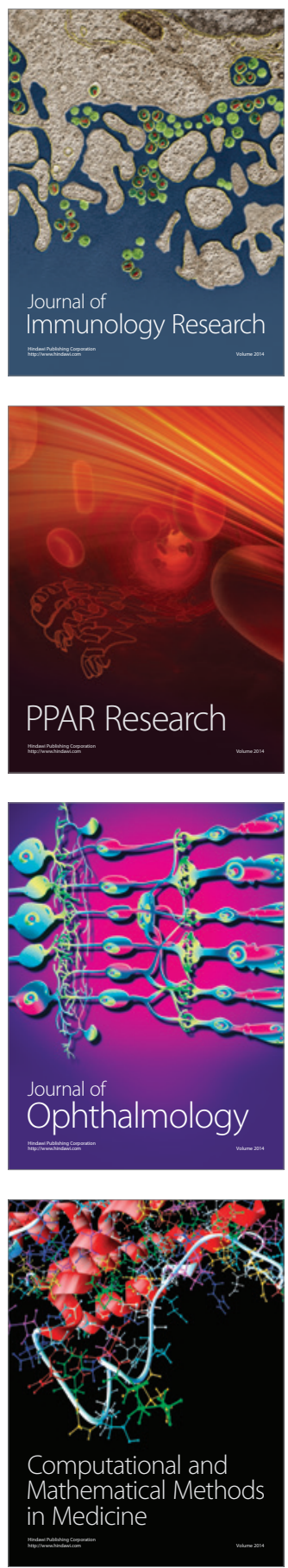

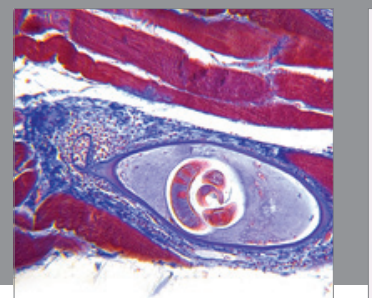

Gastroenterology

Research and Practice
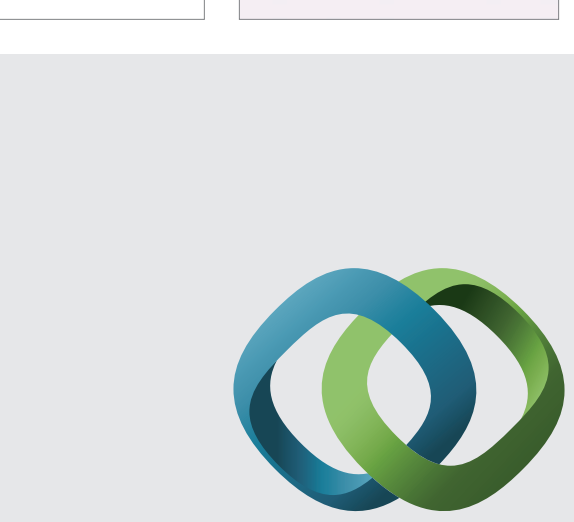

\section{Hindawi}

Submit your manuscripts at

http://www.hindawi.com
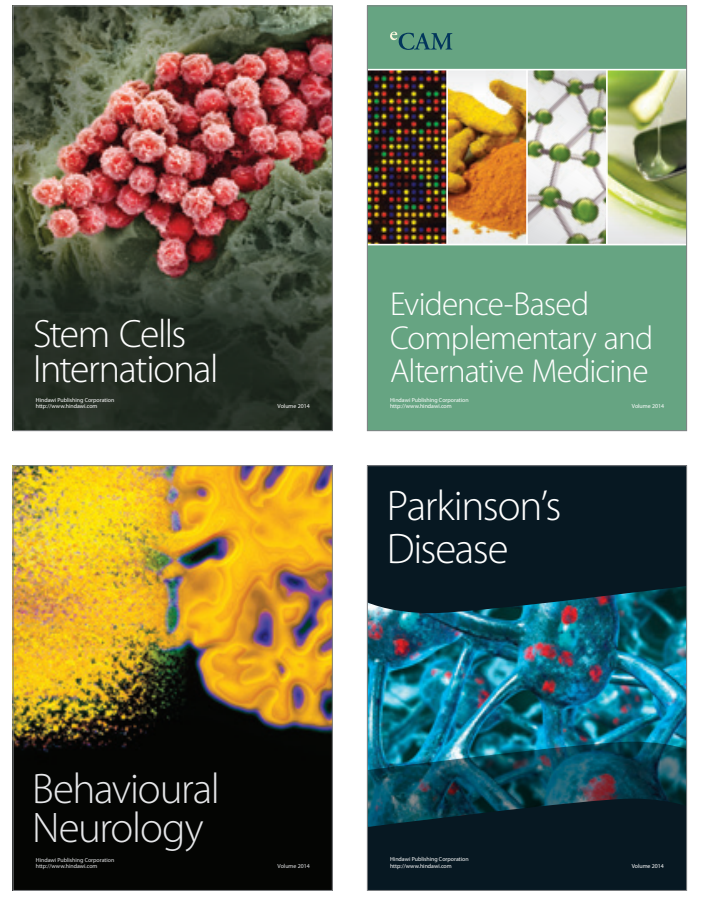
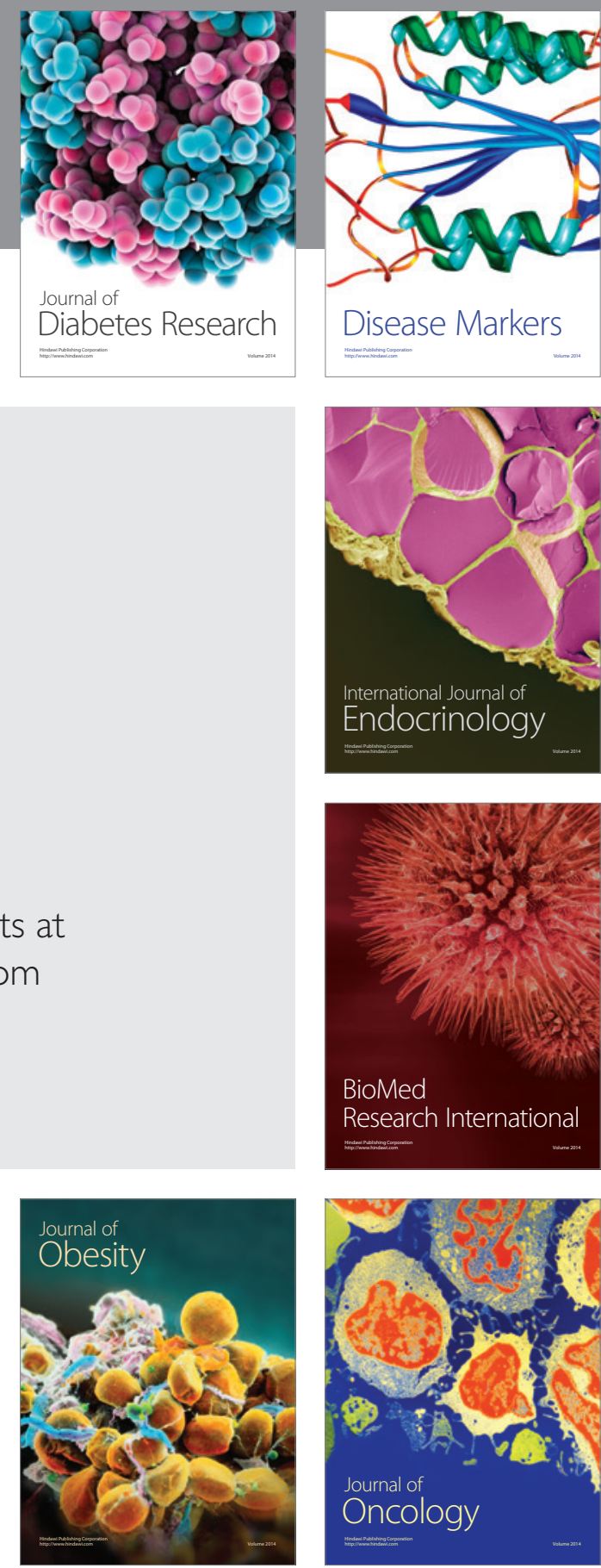

Disease Markers
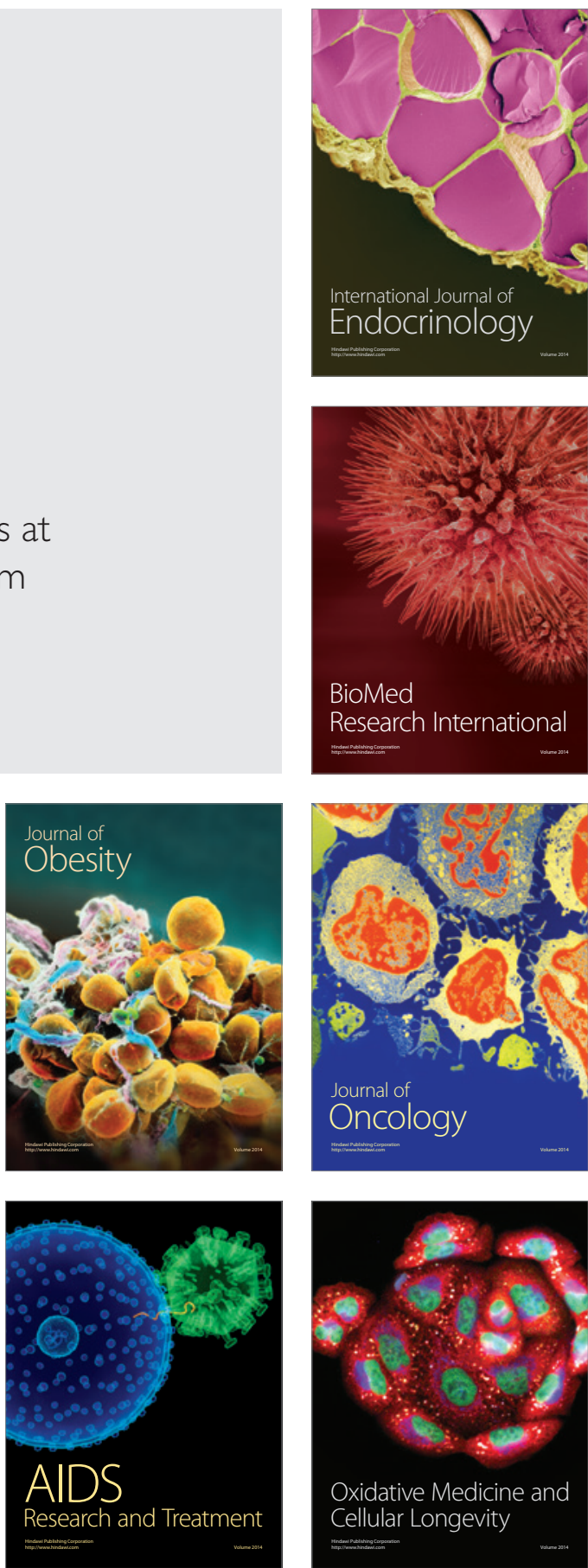